ON THERECORD

(If evolution is true, why are there still monkeys?"

Popular US talk-show host LarryKing interrogates philosopher Barbara Forrest on intelligent design.

"This deals a serious blow to the idea that the placebo effect is a purely psychological phenomenon."

Jon-Kar Zubieta of the University of Michigan on his research that shows placebos can trigger the release of natural painkillers in the brain.

Sources: CNN, Scientific American

\section{SCORECARD}

A Iraqi marshes The United Nations finds that Iraq's devastated marshlands are making a "phenomenal" recovery. Being bogged down in Iraq is, in this case, a good thing.

\section{Hot beverages Forget fruit and vegetables - the number} one source of antioxidants in the US diet is coffee. And if that's not to your taste, black tea came steaming in at number two, beating bananas and dry beans.

$\checkmark$ Hairdressing The sprays, solvents and dyes used by hairdressers may be doing more than fashioning the lateststyles for their clients. An occupational study reveals that members of the profession in the United States are among the mostlikely to develop Alzheimer's or motorneuron diseases.

\section{NUMBER CRUNCH}

20 comets were discovered by Charles Messier, the eighteenthcentury astronomer dubbed the "comet ferret" by King Louis XV of France.

32 comets were discovered by Carolyn Shoemaker, the world's most prolific comet-hunter using ground-based telescopes.

1,000 comets have been discovered by the Solar and Heliospheric Observatory spacecraft so far.

IMAGE UNAVAILABLE FOR COPYRIGHT REASONS

\title{
Satellite view alerts China to soaring pollution
}

Visitors to hazy Beijing can see how Chinas industrialization is fouling the air. Now data suggest that the situation is even worse than it looks, and pollution levels are rising.

Direct satellite measurements of a key pollutant - nitrogen dioxide - are reported in this issue (see page 129). The data show that concentrations of nitrogen dioxide in the atmosphere over China have risen by $50 \%$ during the past decade, and the build-up is accelerating.

In the 1990s, China introduced measures such as clean coal technologies to reduce air pollution (see Nature 435, 1152; 2005). Estimates of nitrogen dioxide concentrations still rose by $13 \%$ between 1994 and 2000 - but there were hints of a plateau (D.G. Streets et al. J. Geophys. Res. 108, 8809; 2003). The estimates were made as part of the ACE-Asia aerosol experiment and were based on bottomup' calculations, which add up the fuel burned to gauge the pollutants released.

The satellite data come from the Global Ozone Monitoring Experiment (GOME), launched aboard a European Space Agency craft in 1995, and the Scanning Imaging Absorption Spectrometer for Atmospheric Chartography (SCIAMACHY), launched in 2002. Both experiments measure concentrations of trace gases in the atmosphere from the Earth's surface to about 10 kilometres high, although SCIAMACHY does so at a much higher resolution.

For nearly a decade GOME observations had shown increases in nitrogen dioxide over China at rates far greater than those estimated by the bottom-up measurements. But researchers didn't feel entirely confident about their results until they got the data from SCIAMACHY. "There was an element of pie-in-the- sky to it, says John Burrows at the University of Bremen in Germany, an author on the Nature paper. Burrows originally proposed both instruments: "We wondered, can you see this kind of thing? Now we know you can."

China's emission inventories may have failed to take account of sources of pollution such as cars, whose numbers doubled in the country between 1995 and 2002 . "New sources have stepped in to take the place of old ones," says another member of the Bremen team, environmental physicist Andreas Richter.

The team's calculations depend on an assumption about how nitrogen dioxide concentrations vary vertically in the atmosphere. "But this should not affect measurements of trends," Richter says.

"The satellite observations are a good starting point to tell us where to correct the predictions," says Tami Bond, an environmental scientist at the University of Illinois, UrbanaChampaign, who worked on the ACE-Asia inventory. However, she adds, "they don't tell you exactly what is happening".

The extent of the increase surprises Jianzhong $\mathrm{Ma}$, an atmospheric chemist at the Chinese Academy of Meteorological Sciences in Beijing, who next year will begin a study of air pollution and aerosols. He hopes that groundlevel observations and aircraft sampling will pin down exact amounts of nitrogen oxides. "We need to integrate the methods," he says.

Meanwhile, the satellite researchers say they will hone their data. GOME II is scheduled for launch next autumn, and Burrows is already proposing a geostationary satellite that could observe continuously, reducing uncertainties about daily fluctuations.

David Cyranoski 